\title{
A Política Pública de Saúde Mental em um CAPS-AD: representações sociais de usuários
}

\author{
Sulyanne da Silva Ferreira* \\ Tais Bleicher**
}

\begin{abstract}
Resumo
O presente estudo tem como base a perspectiva da política pública de Saúde Mental. O objetivo deste ensaio foi apresentar as representações sociais dos usuários sobre a política de saúde mental de uma cidade do estado do Ceará. Tratou-se de um estudo qualitativo, que tem como referencial teórico-metodológico a Teoria das Representações Sociais. Para a coleta de informações foram realizadas entrevistas semiestruturadas. No que diz respeito à análise das entrevistas, adotou-se o método de Análise de Conteúdo Temática. As hipóteses direcionam-se à concepção de que a forma de organização do CAPS AD III de uma cidade do estado do Ceará está pautada nos pressupostos organicistas de atenção, o que talvez seja um dos indicativos da dificuldade de apreender um discurso amplo que englobe a complexidade do sujeito. Conclui-se haver a necessidade de reformulação de estratégias de intervenção das terapêuticas, bem como das diretrizes para um melhor aperfeiçoamento do atendimento aos usuários do sistema.
\end{abstract}

Palavras-chave: Políticas públicas; Saúde mental; Cuidados de saúde.

\section{Abstract}

The present study is based on the public policy perspective of Mental Health. The present essay was presented as social representations of users about a mental health policy of CAPS AD III of a municipality of Ceará. It was a qualitative study, which has as theoretical-methodological reference the Theory of Social Representations. For the collection of information, semi-structured interviews were carried out. Regarding the analysis of the interviews, the Thematic Content Analysis method was adopted. The hypotheses are directed towards the awareness of an organization form of the CAPS AD III of a city of the state of Ceará in the organic assumptions of attention, which is perhaps indicative of the difficulty of assuming a broad discourse that includes one of the subject. It is concluded that there is a need to reformulate therapeutic intervention strategies, as well as the guidelines for a better improvement of the service to the users of the system.

Key-words: Public Policy; Mental Health; Health Care.

* Psicologia Centro Universitário Católica de Quixadá

** Professora da Universidade Federal de São Carlos. Mestre em Psicologia Clínica e Cultura - Universidade de Brasília (UnB). Doutora em Saúde Coletiva (UFC/UECE/UNIFOR), com estância doutoral na Universidade Complutense de Madrid - UCM. 


\section{Introdução}

Os Centros de Atenção Psicossocial (CAPS), como organizadores da rede comunitária de cuidados, têm como estratégia primária a condução local dos programas e políticas de saúde mental, por meio do desenvolvimento de projetos terapêuticos e comunitários. Os CAPS contribuem crucialmente para trabalhos relacionados às equipes de Agentes Comunitários de Saúde, bem como das equipes de Saúde da Família na atenção domiciliar. No âmbito da Saúde, são colocados diferentes desafios, os quais apresentam uma complexidade que exige esforços de diferentes especialidades. Desta forma, os CAPS foram ampliando-se, ao longo da história, em todo o território nacional e produzindo outras modalidades, como a de Álcool e Drogas e a Infantil (Brasil, 2004).

Especificamente, a emergência das políticas públicas sobre álcool e outras drogas no conjunto das diretrizes em saúde mental no Brasil, surge no século XX, quando estes passam a ser considerado um problema social. Isto é, quando se tornam uma preocupação para alguns setores sociais, uma vez que surgem como um fenômeno considerado temível, perigoso e ameaçador para a ordem social e principalmente para a saúde pública (Brasil, 2005). Esse contexto levou a proposição de estratégias, tanto pelo SUS (Lei 8.080/90), quanto pela Reforma Psiquiátrica Brasileira (Lei 10.216/01), para a instituição de dispositivos de cuidados aos usuários de álcool e outras drogas, o CAPS AD, entre outros dispositivos de atenção e cuidado para este público (Brasil, 2005).

Muitas leis e normativas que vieram posteriormente traçaram as diretrizes para as políticas de álcool e drogas, que, obviamente, tem suas peculiaridades locais. Desta forma, a expansão e interiorização dos CAPS, especialmente na região Nordeste, deram-se de forma maciça no período de 2002 a 2010. De modo particular, no que diz respeito à implantação de CAPS específicos, o CAPS III atravessou desafios de expansão, por se tratar de um serviço de maior complexidade da rede. O CAPS AD deste município do CE adota a categoria III, e sua implantação ocorreu apenas em 2014.

Diante das reflexões acerca da política pública de saúde mental para álcool e outras drogas, e das inquietações quanto a sua efetividade, o presente estudo tem como desígnio primário conhecer o modo pelo qual esta política afeta seus usuários. Objetiva-se apresentar as representações sociais dos usuários sobre a política de saúde mental da rede, especificamente o CAPS AD III de um município do Ceará.
A criação de políticas nacionais para álcool e outras drogas no Brasil, administrativamente, está ligada ao Ministério da Saúde, ocasionando como consequência um maior destaque aos seus aspectos sanitários, em detrimento dos sociais. Contudo, os variados usos de drogas são complexos, necessitando de articulação de diversos campos de saber, categorias profissionais e intervenções que comtemplem o apoio integral aos usuários desta política pública.

Portanto, tendo como base de que é o usuário, tomado como sujeito da política pública, que deve guiar sua construção, demos ênfase, neste ensaio, especificamente, às representações que os usuários construíram por meio da experiência do uso de um equipamento da política pública de saúde mental. Por meio deste estudo, busca-se contribuir para a construção de saberes sobre políticas de saúde mental de um município do Ce. Especialmente, as intervenções alusivas a dependentes de substâncias psicoativa.

\section{Material e método}

Para este trabalho, utilizamos como referencial teórico-metodológico a Teoria das Representações Sociais. Para Jodelet (2001), os sujeitos têm necessidade de conhecer seu contexto, ajustarem-se, conduzir-se, identificar-se e resolver problemas que a sociedade impõe. Uma vez que as representações sociais dependem da ordem social, é preciso conhecê-las. Isto porque existe dependência da ordem social. É por meio dessa relação com os outros e com o mundo que se pode nomear um conjunto de práticas da realidade cotidiana.

Trata-se de um estudo de cunho qualitativo e foi aprovado pelo Comitê de Ética em Pesquisa da Faculdade Católica Rainha de Sertão, sob o CAAE: 51896615.3.0000.5046 e CEP: 1.410.828.

A pesquisa foi desenvolvida em um Centro de Atenção Psicossocial Álcool e Drogas Alpendre - CAPS AD III, de um município do estado do Ceará. Os procedimentos de levantamento de dados empregados para perfazer este estudo foram, primeiramente, a revisão bibliográfica e documental acerca do tema selecionado, tomando como base as Políticas Públicas de Saúde Mental, especificamente ao que concerne ao Centro de Atenção Psicossocial Álcool e Drogas - CAPS AD e à Reforma Psiquiátrica.

A fim de verificar as representações sociais dos usuários acerca da rede de atenção ao usuário da política pública de saúde mental, para os casos de álcool e outras drogas, e qual sua importância no Plano Terapêutico Singular dos pacientes, foram realizadas entrevistas se- 
miestruturadas com os usuários do CAPS AD III que se encontravam em tratamento.

Utilizou-se o método de entrevistas semiestruturadas por adotar um caráter semiaberto de respostas não condicionadas a uma linearidade de questões padronizadas (Manzini, 1991). Este método é baseado em um roteiro de questões centrais do tema que decorrem de teorias e hipóteses, as quais são, ao longo da entrevista, complementadas por outras questões pertinentes às particularidades trazidas pelo entrevistado. Este método auxilia na produção do discurso do entrevistado, equiparando-se ao enfoque proposto acerca da Teoria das Representações Sociais (Moscovici, 2003).

Foi realizada uma amostra por conveniência, de usuários que participavam regularmente das atividades e tratamento dispostos no CAPS AD, e que aceitaram participar da pesquisa. Optou-se por não usar critérios de faixa etária e de gênero na estruturação da pesquisa. Para a realização e obtenção dos objetivos da pesquisa, foram entrevistadas 06 (seis) pessoas, que compõem o quadro de pacientes do CAPS AD do município em questão. Para a escolha dos usuários que participaram das entrevistas fez-se necessário a análise dos prontuários para a verificação do período em que estavam em processo de tratamento, bem como o quadro diagnóstico.

No que diz respeito à análise das entrevistas foi adotado a metodologia de Análise de Conteúdo Temática (Bardin, 1977), a partir da criação de categorias centrais sobre o tema. Nesta perspectiva, a análise se estruturou por meio da organização de três fases complementares, a saber: a pré-análise, a exploração do material e o tratamento dos resultados, que diz respeito à inferência e a interpretação (Bardin, 1977).

Para a análise foram eleitas duas grandes categorias para estudo das representações sociais, quais sejam, a Medicina e a Psicologia, por meio das seguintes indagações: 1) Qual é, em sua opinião, a importância do tratamento promovido pela Medicina? 2) Como você vê em seu tratamento o uso de medicamentos? 3) Qual é, em sua opinião, a importância do tratamento realizado pela Psicologia? 4) Como você vê em seu tratamento o trabalho por meio da escuta da Psicologia? Estes temas foram complementados por outras questões pertinentes, de acordo com as particularidades da entrevista.

\section{Resultados e discussão}

No presente estudo, participaram seis usuários da política de saúde mental para álcool e outras drogas. Embora não houvesse exigência quanto ao sexo dos en- trevistados - de modo que, a escolha dos usuários para as entrevistas foram daqueles que estavam integrando as atividades no dia agendado para as entrevistas - participaram das entrevistas usuários do sexo masculino, com faixa etária de 20 a 54 anos. Com relação à escolaridade, o grau mais avançado é o de ensino médio completo, entretanto, a grande maioria dos entrevistados tinha o ensino fundamental incompleto. Os diagnósticos empregados aos sujeitos entrevistados eram relativos ao uso abusivo de álcool e outras drogas. O período de tratamento dos sujeitos entrevistados no CAPS AD variou de um mês a 04 anos

Tabela 1. Características sociodemográficas dos usuários do CAPS AD III entrevistados.

\begin{tabular}{|c|c|c|c|c|}
\hline $\begin{array}{c}\text { Usuários } \\
\text { do CAPS AD } \\
\text { III }\end{array}$ & Idade & $\begin{array}{l}\text { Escolari- } \\
\text { dade }\end{array}$ & $\begin{array}{l}\text { Tempo de } \\
\text { Tratamen- } \\
\text { to }\end{array}$ & $\begin{array}{l}\text { Quadro } \\
\text { Diagnós- } \\
\text { tico }\end{array}$ \\
\hline $\begin{array}{c}\text { Entrevistado } \\
\mathrm{n}^{\mathrm{o}} 1\end{array}$ & 53 & $\begin{array}{c}\text { Ensino } \\
\text { Médio } \\
\text { Completo }\end{array}$ & 18 meses & F10 \\
\hline $\begin{array}{c}\text { Entrevistado } \\
\mathrm{n}^{\circ} 2\end{array}$ & 52 & $\begin{array}{l}\text { Ensino } \\
\text { Funda- } \\
\text { mental } \\
\text { Incom- } \\
\text { pleto }\end{array}$ & 19 meses & F10 \\
\hline $\begin{array}{c}\text { Entrevistado } \\
\mathrm{n}^{\circ} 3\end{array}$ & 45 & $\begin{array}{c}\text { Ensino } \\
\text { Funda- } \\
\text { mental } \\
\text { Incom- } \\
\text { pleto } \\
\end{array}$ & $\begin{array}{l}07 \text { dias } \\
\text { (acolhi- } \\
\text { mento) }\end{array}$ & F10 \\
\hline $\begin{array}{c}\text { Entrevistado } \\
\mathrm{n}^{\circ} 4\end{array}$ & 21 & $\begin{array}{l}\text { Ensino } \\
\text { Funda- } \\
\text { mental } \\
\text { Incom- } \\
\text { pleto }\end{array}$ & 02 meses & $\begin{array}{l}\text { Sem } \\
\text { diagnós- } \\
\text { tico }\end{array}$ \\
\hline $\begin{array}{c}\text { Entrevistado } \\
\mathrm{n}^{\circ} 5\end{array}$ & 19 & $\begin{array}{l}\text { Ensino } \\
\text { Médio } \\
\text { Incom- } \\
\text { pleto } \\
\end{array}$ & $\begin{array}{l}03 \text { dias } \\
\text { (acolhi- } \\
\text { mento) }\end{array}$ & F19.9 \\
\hline $\begin{array}{c}\text { Entrevistado } \\
n^{\circ} 6\end{array}$ & 36 & $\begin{array}{l}\text { Ensino } \\
\text { Médio } \\
\text { Incom- } \\
\text { pleto }\end{array}$ & 4 anos & F10 \\
\hline
\end{tabular}

Nota. Dados obtidos com permissão dos usuários e gestor da instituição.

Dos resultados das entrevistas foram delineadas as seguintes categorias: Visão da terapêutica médica como um trabalho clínico e farmacológico; Medicalização da 
vida; Psicologia a serviço da Medicina: a reprodução do modelo estadunidense; $\mathrm{O}$ aspecto lúdico de um tratamento para adultos: os grupos e Tratamento Moral; Abstinência como ideal de tratamento; Reabilitação Psicossocial.

\section{Visão da terapêutica médica como um trabalho clínico e farmacológico}

A concepção de CAPS que atenda aos ideais de Reforma Psiquiátrica apresenta como uma de suas diretrizes um tratamento baseado na clínica ampliada, isto é, um tratamento com estratégias de recursos humanos e tecnológicos que vão além do uso, unicamente, de consultas e de medicamentos (Brasil, 2004). As práticas de atenção psicossocial e, em especial, na terapêutica médica, no CAPS AD III apresentam um olhar ampliado das formas tradicionais de investigação e compreensão de tratamento dos transtornos mentais.

Nas narrativas dos usuários são apresentadas a terapêutica médica, não só no seu aspecto puramente biológico e farmacológico de tratamento e a posição de escuta clínica do sujeito. Tal qual nas seguintes falas:

O nosso médico, que é o meu, que é o doutor daqui do CAPS, é uma ótima pessoa, muito atencioso, escuta a gente, aconselha, o que ele pode fazer ele faz a favor da gente para contribuir. A gente conversa com ele, conta o que tá acontecendo, a gente explica tudo para ele. E ele também dá as palavras dele. É assim que funciona. (Entrevista $\left.n^{\circ} 1\right)$

Ele dá muito conselho à gente, né? Acho bom. (...) Igual eu queria se matar, ele perguntou o porquê, qual foi o motivo. Conversamos, né? E ficamos... Achei ele bem legal, o médico. Não tenho nada a dizer [mal] dele não. (Entrevista $\mathrm{n}^{\circ} 4$ )

(...) ele me atendeu ótimo, ele conversou comigo, passou os remédios para mim, normal e tudo bem. (...) Ele perguntou o que foi que eu usei, perguntou... as coisas que eu usei e tudo. O que foi que eu fiz... as coisas. O que eu passei. Aí eu disse para ele como foi. (Entrevista n ${ }^{\circ} 5$ )

Em geral, esta forma de atenção ao usuário lança à ideia de perceber o sofrimento deste sujeito em sua singularidade. Esta diretriz está nas proposições e indicativos do Ministério da Saúde (Brasil, 2004). O manual de Saúde mental do SUS: os centros de atenção psicossocial, no que concernem às questões que dizem respeito às terapêuticas propõe que, em todos os modos de atenção, tais terapêuticas devem ter estabelecido em suas metas que "é preciso criar, observar, escutar, estar atento à complexidade da vida das pessoas, que é maior que a doença ou o transtorno" (p. 17). Para tanto, o estabelecimento de atenção ao usuário pela terapêutica médica, de algum modo, prima por atentar aos diferentes aspectos que dizem respeito à vida singular do sujeito, estendendo-se dos preceitos puramente biomédicos para a compreensão da problemática que se apresenta.

\section{Medicalização da vida}

A categoria Medicalização da Vida foi identificada em diferentes narrativas. Esta categoria é caracterizada pelo englobamento de implicações do discurso médico e suas práticas afins (incluindo o uso de fármacos), presentes no cotidiano e rotina de vida do usuário. Aparece nas falas dos usuários, conforme podemos observar:

Eu fico mais... Calmo. Essas coisas assim, né? Relaxado. Eu sou muito estressado, qualquer coisinha eu me estresso. Aí eu tomo Diazepam e mais dois comprimidos, que eu esqueci o nome. (Entrevista no ${ }^{\circ}$ ).

O medicamento eles me dão pra mim relaxar, pra mim relaxar minha mente, pra mim não sentir vontade de usar droga e outra, pra mim relaxar mais, pra mim deitar, pra mim cochilar, pra mim não sentir vontade de usar droga, pra mim comer mais. Tá entendendo? (Entrevista no 5 )

Freitas e Amarante (2015) apresentam estudos que corroboram com estes resultados. Estes autores apontam que, em nosso cotidiano, no exercício de nossas práticas e experiências individuais, dificilmente fazemos algo sem que para isso recorramos a normas que nos são estabelecidas no que diz respeitos ao saudável e ao patológico. Ao cumprirmos as normas que nos são incutidas, incorporando o discurso médico no nosso cotidiano, sentimo-nos protegidos.

"Componentes inerentes à existência (o Dasein heideggeriano) ganham novas formulações: a angústia, por exemplo, se transforma em transtorno de ansiedade; e a finitude ou o ser-para-morte, em transtorno com essa ou aquela designação científica. Tal processo passou a ser conhecido como medicalização de existência ou medicalização da vida cotidiana (Freitas \& Amarante, 2015, p. 12)."

É pertinente enfatizar que as representações apresentadas pelos usuários acerca da terapêutica médica coa- 
dunam com a crítica da medicalização da vida apresentada por diferentes pesquisadores, a saber, Desviat (2018), Lobo (2013) e Whitaker (2017), que se dedicam ao estudo dos fenômenos da problemática da medicalização, suas consequências individuais e sociais e os sentidos atribuídos a uma ordem cujo caráter é biomédico. Em última instância, trata-se da tentativa de transformação do sofrimento psíquico de um estado considerado indesejável ou perturbador em estados saudáveis, mas por uma via simplista, que ignora a complexidade do processo saúde-doença.

\section{Psicologia a serviço da Medicina}

As representações que os usuários possuem da terapêutica psicológica promovida pelo CAPS AD III do município em questão partem do ponto de vista individualista e reducionista do problema de saúde, e, em especial, o problema decorrente do uso de álcool e outras drogas. Esta proposição pode ser visualizada quando um dos usuários traz em suas narrativas o seguinte:

É porque, assim, quem já tá acolhido aqui, tem, semanalmente, psicólogo. Ela atende, pergunta como é que você tá, se tá bem, aí vai levando, vai orientando, começa com as sequências do uso, das medicações, e várias coisas. (Entrevista $n^{\circ}$ 6)

Ela conversa mais sobre como anda sua vida, se você tá reagindo à medicação, se você tá bem. (Entrevista $n^{\circ}$ 6)

Ao remontar à prática psicológica no Brasil, em suas primeiras atuações no âmbito da Saúde em Ações Integradas de Saúde - AIS, o que se identificou são atuações embasadas no modelo de psicologia da saúde estadunidense, a qual aderia um método calcado no paradigma biomédico (Gioia-Martins, 2012). De acordo com Trindade e Teixeira (2007), a psicologia da saúde, em seu corpo teórico, possui atualmente duas perspectivas, a saber, uma tradicional e outra de um viés crítico de ações em Saúde. O modelo de Psicologia estadunidense comporta as ações em Saúde embasadas em sua dimensão tradicional. Em termos práticos, este modelo, que se diz, biopsicossocial, frequentemente adota metodologias quantitativas de investigação de comportamentos saudáveis e de risco, direcionando seu foco aos valores preditivos e os determinantes psicológicos da doença. Perde-se a dimensão do sujeito.

Nas falas apresentadas, parece haver um direcionamento da escuta psicológica para o acompanhamento das condutas biomédicas, nesse sentido, aproximando-se de uma Psicologia da Saúde mais tradicional, na perspectiva de Trindade e Teixeira (2007). Seriam necessários outros desenhos metodológicos de pesquisa, que incluíssem os próprios profissionais do serviço, para avaliar se é realmente essa diretriz que orienta o trabalho psicológico na instituição.

\section{O aspecto lúdico de um tratamento para adultos: os grupos}

A partir da fala de um usuário, surgiu a necessidade de discussão sobre a natureza dos grupos psicoterapêuticos, pois, para ele, suas técnicas são representadas como sendo intervenções de aspecto lúdico, sem clara proposta terapêutica. Eis sua narrativa sobre a técnica grupal promovida pelo profissional de Psicologia:

(...) tipo uma brincadeira, essas coisas assim. (...) Elas lê lá e nós... tipo umas brincadeiras, por exemplo, elas lê lá e depois a gente coisa, como é? Ela lê lá e nós... responde. E assim vai. Tem as brincadeira, que elas faz, as pergunta e nós responde. E assim vai. (Entrevista $n^{\circ} 4$ )

A clínica grupal destaca-se, no contexto da Reforma Psiquiátrica, como resultado de iniciativa da reforma das instituições totais, direcionada ao trabalho com doentes mentais. Suas atividades estavam baseadas em intensas ações direcionadas ao coletivo, a fim de superar os movimentos de segregação e enclausuramento da loucura (Lancetti, 1993). Este aponta que, na experiência realizada em Santos, primeira cidade brasileira a extinguir os manicômios, substituiu-se a ordem segmentária pela ordem coletiva, em que esta última traz como estratégia os diferentes grupos e a participação política, isto é, dispositivos de ordem coletiva, democrática e terapêutica.

Teóricos de renome - Bion (1975), Foulkes e Anthony (1967), Moreno (1974) e Pichon-Rivière (2000) - se propõem a discutir a temática de grupos psicoterapêuticos. Aqui, o destaque se dará à perspectiva de Vinogradov e Sophia (1992), na obra intitulada Psicoterapia de grupo: um manual prático. Estes apontam que "a psicoterapia de grupo é um tratamento tão efetivo quanta a psicoterapia individual, no tratamento de vários transtornos psicológicos" (p. 08). Para tanto, a efetividade da técnica de psicoterapia em grupo só se torna possível a partir do atendimento de características flexíveis, mas de grande valia, a saber, o setting, os objetivos e a estrutura de tempo.

Nesta perspectiva, o destaque se dará em relação ao aspecto dos objetivos que devem ser alcançados pela 
técnica de grupos, a qual deve estar clara e se estender a todos os participantes. Contudo, os objetivos variam de grupo para grupo, tomando como bases norteadoras aspectos que vão desde o público, a idade, a temática, entre outros fatores, mas que de modo geral devem atender aos objetivos mais importantes de todo grupo. Tais objetivos estão basicamente direcionados a oferecer educação, socialização, apoio, bem como alterar comportamentos específicos, na perspectiva apresentada pelos autores (Vinogradov \& Sophia, 1992). Outras perspectivas teóricas dentro da Psicologia e mesmo da Psicanálise aproximam os objetivos da terapêutica individual e da grupal.

Embora não seja possível reduzir a compreensão do que é um grupo terapêutico a partir da fala de um único usuário, dada a importância das terapias grupais no campo da Saúde Mental, seria necessário realizar novas pesquisas, incluindo outras metodologias e mais sujeitos, com o fim de averiguar se os grupos terapêuticos estão alcançando sua real finalidade.

\section{Tratamento Moral}

A elaboração da categoria Tratamento Moral foi definida por englobar aspectos que dizem respeito ao modelo de tratamento atribuído aos usuários do CAPS AD III de um município do Ceará. As representações sociais dos usuários sobre o tratamento que recebem remetem ao modelo asilar. Senão, vejamos:

Porque aqui, nosso contato com a família aqui é uma vez por semana, a quarta-feira, né? Porque não pode, né, a família tá todo dia, não pode ter contato com telefone, não pode ter com a família. (Entrevista $n^{\circ} 6$ )

Apreende-se que o tratamento proposto pelo CAPS AD III toma como molde o tratamento moral pineliano, tanto como em sua origem hospitalar, quanto em suas derivações e atualizações como praticadas em comunidades terapêuticas (Bleicher \& Viana, 2012). O tratamento orientado a partir de tal modelo traz a concepção de que, para se recuperar, faz-se necessário o distanciamento temporário do usuário de seu ambiente, isto é, faz-se necessário afastá-lo de tudo aquilo que o corrompe e gera adoecimento.

As bases do "tratamento moral", do qual pode ser atribuído como a raiz introdutória da loucura como um fenômeno que diz respeito a uma ordem médica e marca o início da Psiquiatria, trazem como pressupostos o restabelecimento da razão desviada (Pereira, 2004). Foucault (1975) afirma ser o tratamento moral em Doença Mental e Psicologia, um controle ético exercido sobre a loucura, mais do que, propriamente, uma intervenção terapêutica. Para tanto, tais internações representavam um regime moral cujas estratégias tinham um caráter de precaução e exclusão social.

Assim, aparentemente, existe uma linearidade entre: o modelo manicomial, tal qual defendido por Pinel; as comunidades terapêuticas, que continuam isolando o sujeito de seu contexto, e alguns CAPS, que não avançaram na mudança cultural e subjetiva de sua equipe.

As críticas abaixo, referentes às comunidades terapêuticas também poderiam ser feitas para CAPS que adotam a lógica da segregação:

"As comunidades terapêuticas não permitem verdadeira liberdade ao paciente, apenas uma ilusão de liberdade, já que ele continua internado e regido pelas diretrizes gerais da instituição e da equipe de saúde; As comunidades terapêuticas não são uma cópia menor da sociedade, portanto não podem ser consideradas um treino para esta. Frequentemente, ao sair delas, os pacientes se encontram despreparados para lidar com a vida real" (Bleicher, 2015, p. 59).

No que se trata a liberdade ao paciente no CAPS AD III em questão, ela é restringida, uma vez que o paciente é regido pelas leis gerais da equipe de Saúde, e, de forma mais ampla, da própria instituição, a despeito da singularidade do seu caso.

\section{Abstinência como ideal de tratamento}

Embora o CAPS AD III tenha aderido em suas intervenções a um modelo progressista, que trabalha na perspectiva de redução de danos, o que prevalece nas narrativas dos pacientes é a perspectiva de tratamento por meio da abstinência. O que pode ser identificado na seguinte fala:

Às vezes eu caio, tento me levantar, né? Já tô com dez dias que tive uma recaída, mas voltei a tomar meus medicamentos, e tô me segurando. Mas tá dando certo. (Entrevista $\mathrm{n}^{\circ}$ 1)

Aparentemente, apesar da proposta progressista dos CAPS, não houve uma mudança cultural em relação ao uso de drogas. Permanecem as heranças das ações para álcool e outras drogas sob viés proibicionista, baseadas na repressão, sendo a abstinência uma condição para a adesão ao tratamento (Alves, 2009).

Assim como em outros países do mundo, os movimentos proibicionistas no Brasil foram muito importantes 
na primeira metade do século XX. Quanto às intervenções para a proibição do álcool no país, em 1920, foi instituída a Liga Contra o Álcool, como sendo o "primeiro grito de guerra contra o álcool” (Souza, 2004). As medidas controladoras do uso de drogas, lícitas e ilícitas, tinham caráter repressivo, em um modelo moral/criminal se atrelaram ao modelo binário saúde/doença. Portanto, o enfrentamento se dava, respectivamente, pelo encarceramento e tratamento de caráter biológico. No entanto, as intervenções proibicionistas não alcançaram seu ideário de supressão do consumo de álcool e drogas. Em contraposição a elas, já no contexto da Reforma Sanitária, o Brasil adotou outras estratégias de saúde denominadas de redução de danos, não mais repressivas e controladoras (Alves, 2009).

As estratégias e alternativas políticas de redução de danos resultam, historicamente, de uma medida de prevenção decorrente da epidemia do contágio por HIV, de doenças sexualmente transmissíveis e de hepatite, direcionadas para usuários de drogas injetáveis. Em geral, a estratégia de redução de danos trata-se de uma forma de lançar ao usuário de droga uma alternativa que descentralize o ideal de abstinência, a fim de que se possa privilegiar a liberdade individual do desejo de fazer uso ou não de substancias psicoativas (Ayres, Júnior, Calazans \& Filho, 2003).

Portanto, as hipóteses que podemos lançar, quanto à falta de conhecimento por parte do usuário sobre a política de redução de danos, são as de que: há um fraco desempenho no embasamento da atenção à saúde pelo viés de uma política de redução de danos, a ponto de não deixar explícito para o usuário o real propósito das intervenções que se sucedem. Ou, ainda, esta não é a perspectiva adotada em tal CAPS.

\section{Reabilitação Psicossocial}

A categoria Reabilitação Psicossocial surgiu da necessidade de questionar sobre o lugar que o tratamento proposto por este CAPS AD III atribui ao sujeito da política pública.

O uso de substâncias psicoativas, por si só, está associado a estereótipos, do ponto de vista social. Some-se a isso o estigma relacionado à doença mental, e cria-se uma situação de assujeitamento. $\mathrm{O}$ usuário de substâncias psicoativas estaria, portanto, associado à periculosidade e, ao mesmo tempo, à figura do "dependente", incapaz de conduzir sua própria vida. Perde-se a dimensão do usuário da política pública de saúde mental como cidadão.

Atualmente, existem políticas públicas de saúde mental em defesa do tratamento e reinserção do sujeito acometido de algo que o incapacite. Tais políticas adotam como uma de suas diretrizes a reabilitação psicossocial, de acordo com Oliveira, Fortunato, Farias e Pitta (1996), conceito forjado do processo de Reforma Psiquiátrica, proposta pela Psiquiatria Democrática. Portanto, a reabilitação psicossocial nasce especialmente articulada à clínica das psicoses. No caso dos usuários de substâncias psicoativas, suas histórias de vida são diferentes, uma vez que, frequentemente, apresentam alguma escolarização ou trajetória laboral (Bleicher, 2015).

Podemos identificar nas falas dos usuários deste CAPS AD III que o processo de reabilitação psicossocial tomou contornos, aparentemente, opostos àqueles propostos pelas ideias apresentadas nos movimentos de Reforma Psiquiátrica, o que se pode constatar na seguinte narrativa:

Eu estava sem trabalhar, devido eu estar aqui, mas já voltei às atividades normais, né? Só que eu trabalho na FUNASE e eu ia pro campo, mas devido a esse meu tratamento, eu estou ficando interno, devido os medicamentos, né? Eu não posso subir em escada, eu tomo medicamento meio forte. Mas tá dando certo. (Entrevista $n^{\circ} 1$ )

Estes resultados corroboram os estudos de Kinoshita (2010), onde o autor apresenta o debate de que a estigmatização sofrida pelo doente mental acarretou, historicamente, sua posição apenas como uma posição de doente, anulando, com isto, qualquer possibilidade de ser visto como um sujeito social, isto é, um sujeito que tem seu valor atribuído dentro do campo social de trocas. O autor relaciona tais questões ao processo de reabilitação psicossocial, nos lançando as seguintes indagações: “O que seria reabilitar senão reconstruir estes valores, aumentar o poder contratual do usuário? Criar as condições de possibilidade para que um paciente possa de alguma maneira participar do processo de trocas sociais?" (p. 56).

As questões relativas à reabilitação psicossocial no âmbito da saúde mental, a partir do paradigma denominado por Oliveira e Fortunato (2007) ético-estéticopolítico, devem ser refletidas como uma "desconstrução de práticas silenciadoras e a (re)construção de práticas voltadas para as reais necessidades de pessoas" (p. 158). Esta perspectiva pode ser vista na própria fala do usuário, quando ele nos apresenta sua necessidade de fazer o tratamento e o desejo de permanecer no convívio social:

Eu penso assim, que o tratamento aqui, poderia ser assim: que ou eu ir para casa tomar o medicamento e continuar 
sempre vindo pra cá, e ficar sempre relatando os fatos que tá acontecendo, porque qualquer coisa vocês podem saber, eu estando lá. Se eu estou fazendo alguma coisa com estripulia, ou se voltei a beber, se eu voltei a fazer as coisas que eu fazia, e é isso aí. Porque lá é só eu e minha mãe, não tem quem faça nada para ela, eu lá é quem boto água, boto lenha, eu quem ajudo tudo lá em casa. (Entrevista n ${ }^{\circ}$ )

Podemos constatar a importância da adoção de uma clínica ampliada, comprometida com a escuta e reais necessidades do sujeito, aumentando a oferta de dispositivos de atenção direcionados ao usuário da política pública de saúde mental, favorecendo a reinserção social e a sua singularidade. Este modelo de atuação, de reabilitação psicossocial, prima, portanto, pela liberdade de escolha do sujeito, e consequentemente, possibilitará sua autonomia.

Se tomarmos como base a prerrogativa preconizada pela Portaria No 130 de 26 de janeiro de 2012 (Brasil, 2012, p. 03), acerca da Redefinição do Centro de Atenção Psicossocial de Álcool e outras Drogas 24 h (CAPS AD III) (tipo e modalidade aderidos no município em questão), em especial, no que trata das atividades de reabilitação psicossocial, podemos fazer um paralelo ao que foi apresentado nas narrativas dos usuários. Iremos nos deter ao Art. $6^{\circ}$, o qual remete a questão da "A atenção integral ao usuário no CAPS AD III", onde este aponta algumas atividades a serem desempenhadas pelo centro:

atividades de reabilitação psicossocial, tais como resgate e construção da autonomia, alfabetização ou reinserção escolar, acesso à vida cultural, manejo de moeda corrente, autocuidado, manejo de medicação, inclusão pelo trabalho, ampliação de redes sociais, dentre outros (Brasil, 2012, p. 04).

De modo geral, a necessidade de comprometimento e atenção no que diz respeito à Reabilitação Psicossocial pelos profissionais pode ser sentida pela própria necessidade do usuário de adesão a uma autonomia cidadã, como podemos analisar nas seguintes falas:

É, como eu estava dizendo, eu agradeço muito assim ao CAPS, por que eles estão me dando essa força, essa coragem, por que até hoje eu estou aqui. Vontade de sair, eu tenho vontade de sair pra rua, mas só que eu me seguro muito. Tá me entendendo? Eu me seguro muito pra não sair e estar aqui até esses 15 dias e me curar. Até, quando eu sair, arrumar um trabalho pra mim, um emprego, arrumar uma pessoa pra mim que goste de mim e que me ajude. E sair do mundo da droga, por que esse mundo da droga não leva ninguém a nada mesmo, só leva a pessoa para trás, por que se levasse para frente todo mundo usava, né? Era ou não era? (Entrevista n ${ }^{\circ}$ )

\section{Considerações finais}

Para concluir, cabe destacar que, nas políticas públicas de Saúde Mental, existe um diário enfrentamento de problemas complexos do campo de atuação, ademais quando se trata da atenção ao usuário de substâncias psicoativas. Este é um tema acerca do qual não se podem esgotar as discussões, possibilitando esta pesquisa futuras reflexões dos agentes, gestores, trabalhadores e usuários da política pública de saúde mental.

Por meio do agrupamento das entrevistas e de suas análises, associando as noções extraídas destas às teorizações, debruçou-se por meio de uma reflexão crítica, com base em pressupostos contemporâneos sobre o modelo de política de saúde mental, suas diretrizes, princípios, proposições e o modo de atenção da instituição.

Em geral, foi possível identificar que a terapêutica médica, embora tenha tomado o destaque nas narrativas dos usuários como um tratamento que propõe ações de ordem organicista e farmacológica, apareceu também como uma prática de caráter subjetivante, como um tratamento que engloba um espaço de escuta do sujeito, em um modelo de clínica ampliada. Em contrapartida, a terapêutica psicológica parece desconhecida dos usuários em suas especificidades teórico-práticas.

Seja qual for o modelo de atenção, o sujeito deve ter minimamente conhecimento do funcionamento da política, dos equipamentos de Saúde, e, consequentemente, de seus recursos humanos e tecnológicos para que haja implicações - e não se torne um conjunto de ações alienantes. Nas discussões, inúmeros pontos acerca dos recursos de intervenção surgiram como material de análise. Foi constatado que as técnicas são reconhecidas pelos usuários da política de forma controvertida, uma vez que não conseguem apreender a finalidade da proposta dos tratamentos promovidos, tais como os grupos psicoterapêuticos, inclusive em sua articulação com a política de redução de danos e o processo de reabilitação psicossocial.

Por fim, reitera-se a importância da divulgação de informações sobre os princípios e diretrizes da política de Saúde em geral, quanto ao seu potencial, e, em especial, dos serviços de atenção aos usuários da saúde mental. Tais ações direcionadas aos usuários da política são rele- 
vantes para a construção de políticas públicas, tento em vista que os usuários são os elementos fundamentais para decidir a qualidade e a tipologia da assistência.

\section{Referências}

Alves, V. S. (2009). Modelos de atenção à saúde de usuários de álcool e outras drogas: Discursos políticos, saberes e práticas. Cadernos de Saúde Pública, 25(11), 2309-2319.

Ayres, J. R., Júnior, I. F., Calazans, G. J., \& Filho, H. C. (2003). O conceito de vulnerabilidade e as práticas de saúde: novas perspectivas e desafios. In D. Czeresnia (Org.), Promoção da saúde: conceitos, reflexões, tendências (pp. 117-139). Rio de Janeiro: Fiocruz.

Bardin, L. (1977). Análise de conteúdo. Lisboa: Edições 70.

Bion, W. Experiências com grupos: os fundamentos da psicoterapia de grupo. Rio de Janeiro: Imago/USP, 1975.

Bleicher, T. \& Viana, T. C. (2012). Continuidades e descontinuidades do tratamento moral em modelos de tratamento para toxicômanos. Revista de Psicologia, 3(1), 38-50.

Bleicher, T. (2015). A politica de Saúde Mental de Quixadá, Ceará (1993-2012): uma perspectiva histórica do sistema local de Saúde. Tese (doutorado). Universidade Federal do Ceará, Universidade Estadual do Ceará e Universidade de Fortaleza, Fortaleza, CE.

Brasil. (2004). Ministério da Saúde. Secretaria de Atenção à Saúde. Departamento de Ações Programáticas Estratégicas. Saúde mental no SUS: os centros de atenção psicossocial. Brasília: Ministério da Saúde.

Brasil. (2005). Ministério da Saúde. Secretaria de Atenção à Saúde. DAPE. Coordenação Geral de Saúde Mental. Reforma psiquiátrica e politica de saúde mental no Brasil. Documento apresentado à Conferência Regional de Reforma dos Serviços de Saúde Mental: 15 anos depois de Caracas. OPAS. Brasília, DF.

Brasil. (2012). Portaria n ${ }^{\circ} 130$, de 26 de Janeiro de 2012. Redefine o Centro de Atenção Psicossocial de Álcool e outras Drogas 24 h (CAPS AD III) e os respectivos incentivos financeiros. Diário Oficial da República Federativa do Brasil, Brasília, DF.

Desviat, M. (2018). Coabitar a diferença: da reforma psiquiátrica à Saúde Mental Coletiva. São Paulo: Zagodoni.

Foucault, M. (1975). Doença Mental e Psicologia. Laranjeiras/RJ: Tempo Brasileiro.

Foulkes, S. E., Anthony, E. J. (1967). Psicoterapia de grupo. Rio de Janeiro: Biblioteca Universal Popular.
Freitas, F., \& Amarante, P. (2015). Medicalização em Psiquiatria. (22a ed.). Rio de Janeiro: Editora Fiocruz.

Gioia-Martins, D. F. (2012). Psicologia e saúde: formação, pesquisa e prática profissional. São Paulo: Vetor.

Jodelet, D. (2001). Representações sociais: um domínio em expansão. In: Jodelet, D. (Org.) As representações sociais. (pp. 17-44). Rio de Janeiro: EdUERJ.

Kinoshita, R. T. (2010). Contratualidade e Reabilitação Psicossocial. In: Pitta, A. M. F. (Org.). Reabilitação Psicossocial no Brasil. (pp. 19-26) São Paulo: Hucitec.

Lancetti, A. (1993). Clínica grupal com psicóticos: a grupalidade que os especialistas não entendem. In: Lancetti A. (Org.). Grupos e coletivos. (pp. 155-172). São Paulo, SP: HUCITEC.

Lobo, A. O. (2013). Hacia una Psiquiatría Crítica: excesos y alternativas en salud mental. Madrid: Grupo 5.

Manzini, E. J. (1991). A entrevista na pesquisa social. Didática, 26/27, 149-158

Moreno, J. L. (1974). Psicoterapia de grupo e psicodrama: introdução à teoria e a práxis. São Paulo: Mestre Jou. (Original publicado em 1959).

Moscovici, S. (2003). Representações Sociais: investigação em psicologia social. Petrópolis, RJ: Vozes.

Oliveira, F. B., Fortunato, M. L., Farias, M. C. A. D. \& Pitta, A. M. F. (1996). O que é reabilitação psicossocial no Brasil, hoje? In: Pitta, A. M. F. (Org.). Reabilitação psicossocial no Brasil (pp. 19-26). São Paulo, SP: HUCITEC.

Oliveira F. B. \& Fortunato M. L. (2007). Reabilitação Psicossocial na Perspectiva da Reforma Psiquiátrica. Vivencia, 32, 155-161.

Pereira, M. E. C. (2004). Pinel: a mania, o tratamento moral e os inícios da psiquiatria contemporânea. Rev. Latinoam. Psicopatol. Fundam. 7(3), 113-116.

Pichon-Rivière, E. (2000). O processo grupal. São Paulo: Martins Fontes.

Souza, R. L. (2004). Cachaça, vinho, cerveja: da Colônia ao século XX. Estudos bistóricos, 33, pp. 56-75.

Trindade I., \& Teixeira, J. A. C. (2007). Psicologia nos Cuidados de Saúde Primários. (2a ed.). Lisboa: Climepsi Editores.

Vinogravod, S., \& Yalom, I.D. (1992). O Que É A Psicoterapia De Grupo? In: Psicoterapia de Grupo: um manual prático. (pp.3-15). Vinogravod, S., \& Yalom, I.D. Porto Alegre: Artes Médicas.

Whitaker, R. (2017). Anatomia de uma epidemia: pilulas mágicas, drogas psiquiátricas e o aumento assombroso da doença mental. Rio de Janeiro: Fio Cruz.

Submetido em: 20-8-2017

Aceito em: 20-12-2018 